\section{Original Research}

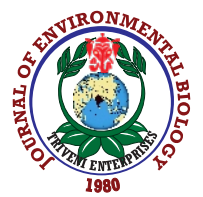

DOI : http://doi.org/10.22438/jeb/41/5/MRN-1219
Journal Home page : www.jeb.co.in $\star$ E-mail : editor@jeb.co.in Journal of Environmental Biology

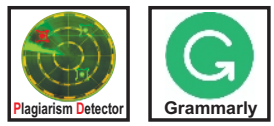

\title{
De-bittering studies of kinnow mandarin (Citrus reticulata Blanco) juice
}

\author{
S. Kumar ${ }^{1 *}$, R. Kumar' and P.C. Sharma ${ }^{2}$ \\ 'ICAR-Central Institute of Post Harvest Engineering and Technology, Abohar-152 116, India \\ ${ }^{2}$ YS Parmar University of Horticulture and Forestry, Solan-173 230, India
}

*Corresponding Author Email : sunil_saini2007@yahoo.com

\section{Abstract}

Aim: The aim of the present study was to evaluate the presence of bittering factors limonin and naringin in kinnow fruits and to elucidate the process of kinnow juice de-bittering.

Methodology: Limonin and naringin concentration was quantified using reverse phase HPLC. Both the constituents were evaluated in various compartments of fruits viz. seeds, albedo, flavedo, pomace and juice. The extracted kinnow juice was assessed for bittering factors during various months of harvesting, as well as during storage with variable $\mathrm{pH}(3,4,5)$ and temperature (low and ambient). Further, various adsorbents were tried on juice to adsorb limonin and naringin in order to elucidate the process of kinnow juice de-bittering.

Results: Limonin and naringin were found to be the highest in seed and albedo portions. The level of limonin decreased with increasing $\mathrm{pH}$ and with low temperature storage comparatively. $X A D-7$ and $X A D-16$ were found to be at par as well as the most effective adsorbents in reducing bitterness compared to rest of the adsorbents tested.

Interpretation: A process has been devised which involves manual removal of peel and seeds followed by treatment of extracted juice with centrifugation and activated carbon to reduce bittering constituents below their threshold levels in the final juice. The process does not require complex set-up of equipment and costly adsorbents.

Key words: Bitterness index, Harvesting time, Limonin, Naringin, Reverse phase HPLC
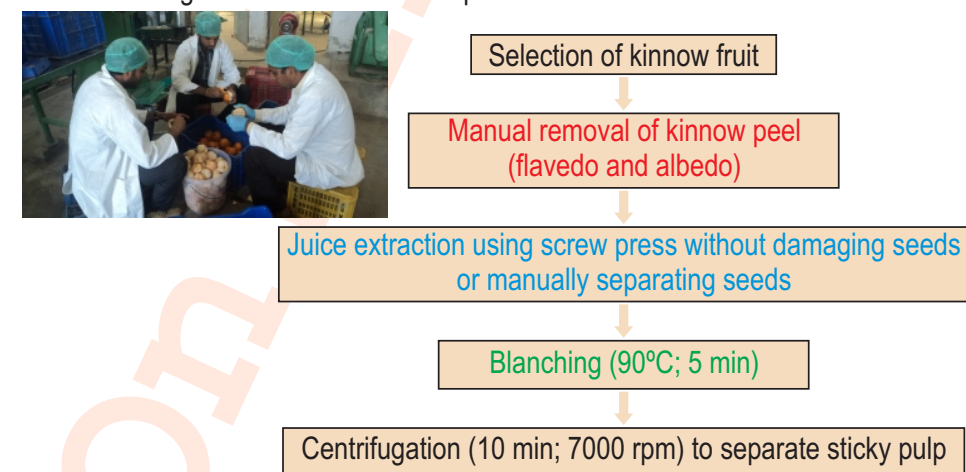

Centrifugation (10 min; 7000 rpm) to separate sticky pulp
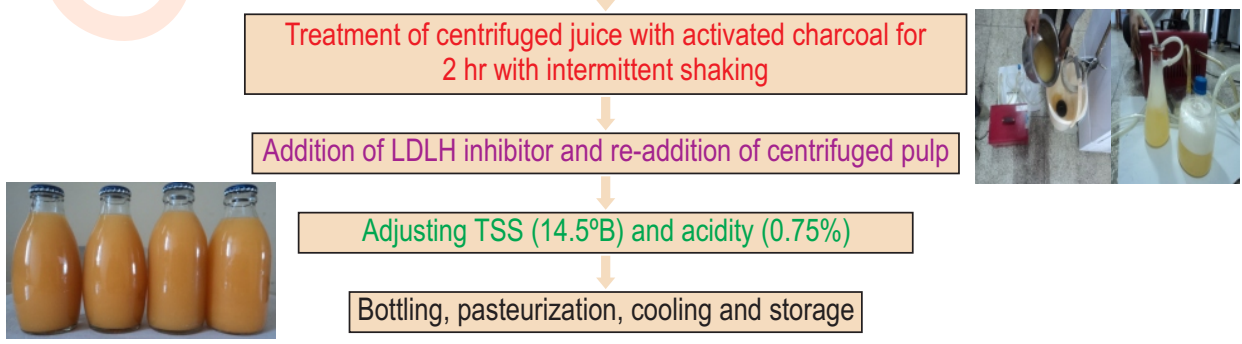

Adjusting TSS (14.5 B) and acidity $(0.75 \%)$

Bottling, pasteurization, cooling and storage

How to cite : Kumar, S., R. Kumar and P.C. Sharma: De-bittering studies of kinnow mandarin (Citrus reticulata Blanco) juice. J. Environ. Biol., 41, 1068-1074 (2020). 


\section{Introduction}

Mandarins are fruits of citrus group belonging to Rutaceae family and are at the center-stage of commercial processing (Putnik et al., 2017). Mandarins represent 22\% of world's citrus production (FAO, 2017) and positioned as second most produced citrus in the world (Putnik et al., 2017). Worldwide mandarin cultivation has elevated remarkably to about 2.4 times from 1990 to 2014, with China as the leading producer and responsible for $54 \%$ of the world's total production in 2014 followed by Spain, Morocco, Turkey, Brazil, and Egypt. Around $50 \%$ of the world's export is done by Spain only (FAO, 2017). India stands third in the production of citrus fruits in the world. Kinnow mandarin (Citrus reticulata Blanco) is an important citrus fruit crop of northern India. Mandarins (including kinnow and oranges) are grown in an area of about 330 thousand ha with an annual production of 3.43 million metric tonns (National Horticulture Board, 2015). Kinnow contributes towards major fruit production in north zone of India in general and particularly in Punjab where total area of 31,800 ha is under kinnow cultivation with the production of 0.6 million metric tonns (Sahota and Kaur, 2015). Among different citrus fruits, kinnow mandarin is one of the major fruit crops with superior characteristics like heavy bearing, wide adaptability, fruit quality and high juice content (Sahota and Kaur, 2015)

Excessive bitter taste in citrus juice is a major problem for citrus processing industries worldwide since it reduces the quality and commercial value of the processed juice (Puri and Kalra, 2005). In fact, this bitterness exists in all citrus juices to more or less extent and generally serves a myriad of functions for plants including plant defense and to prevent herbivory. Limonin and naringin co-exist in most citrus cultivars, but in different amounts, and their threshold levels are different. Both limonin and naringin are primarily responsible for bitterness in processed citrus juices. Naringin (4,5,7-trihydroxyflavonone-7-rhamnoglucoside) is the first to attribute bitterness to the juices and sometimes referred to as initial bitterness (Puri et al., 2005). It ensues in citrus juices when albedo and flavedo of the fruit membrane are squeezed during juice extraction. On the other hand, limonoid bitterness gradually befalls after juice processing from kinnow fruit which is referred to as delayed bitterness and the reaction is catalyzed by limonoate-D-ring lactone hydrolase (LDLH) enzyme owed to formation of limonin (Hasegawa and Maier, 1990; Ferreira et al., 2008; Kumar et al., 2018). Due to bitterness in processed juices, $95 \%$ of kinnow fruits are used for table purpose and only $5 \%$ are processed into juice or juice concentrate rendering market glut and price fall during peak fruiting season (Khandelwal et al., 2006). As a result, both growers and processors suffer huge loss in the absence of suitable low-cost process technology for debittering of kinnow juices. Though, considerable research efforts have been made in the past for detecting and modulating bitterness of both initial and delayed type in citrus juices, but an effective and reliable process has not been developed. These include suppressing agents (Shaw and Wilson, 1985), adsorbents (Singh et al., 2008), enzymatic (Puri et al., 2005; Ferreira et al., 2008), and many more. Some processes are not met with desired success while others are too costly to be adopted by industries. Kinnow mandarin (Citrus reticulata Blanco) juice has pleasant flavor and taste but naturally occurring limonin (a limonoid) and naringin (a flavonoid) are the de-facto bitterness causing chemical constituents that adversely affect consumer acceptability of juice and allied products. Thus, in this research work, studies on the major bittering factors limonin and naringin, in terms of harvesting time, spatial basis as well as during processing were carried out and used finally to elucidate a process for kinnow juice de-bittering.

\section{Materials and Methods}

Raw material : Healthy and external spot free kinnows were harvested from farmer's field of Abohar region, Punjab, India. The experiments were performed during 2014-15 at Horticultural Crop Processing Division, ICAR-CIPHET, Abohar. For quantification of limonin and naringin, harvesting was done at monthly interval from September to April in order to assess the impact of tree fruit ripening on physico-chemical and bitterness related changes. The harvested fruits were washed with $100 \mathrm{ppm}$ chlorinated water and the juice was extracted using screw press after manual removal of peel (flavedo and white albedo) from the fruit. Kinnow seeds were separated from fruits before juice extraction, washed and dried under shade at room temperature. All chemicals and lab accessories used during present investigations were of analytical grade.

Extraction and estimation of bitterness causing chemical constituents : For extraction of limonin from seed or peel of kinnow, $2.5 \mathrm{~g}$ of each tissue was homogenized with $50 \mathrm{ml}$ of Tris buffer $(0.1 \mathrm{M}$; $\mathrm{pH} 7.0)$. The broth was incubated at $35^{\circ} \mathrm{C}$ in a shaker (150 rpm) for $24 \mathrm{hr}$. After $24 \mathrm{hr}$, the resulting extract was filtered through two layers of muslin cloth and bloating paper followed by centrifugation at $7000 \mathrm{rpm}$ for $15 \mathrm{~min}$. The clarified extract was acidified ( $\mathrm{pH} 2.0$ ) with $5 \mathrm{~N} \mathrm{HCl}$, mixed vigorously and kept undisturbed for $15 \mathrm{~min}$. Afterwards, $50 \mathrm{ml}$ of chloroform was added to acidified extract by vigorous mixing and allowed to stand for $30 \mathrm{~min}$ in a separatory funnel. For extraction of limonin from kinnow juice, $50 \mathrm{ml}$ of juice was mixed directly with $50 \mathrm{ml}$ of chloroform and allowed to stand for $30 \mathrm{~min}$. Since limonin is fat soluble, it gets dissolved in chloroform portion while other watersoluble debris remains in water. The decanted chloroform portion was filtered via grade- 1 filter paper; allowed to evaporate and the residue was re-dissolved in 30\% acetonitrile and treated as limonin extract. The juice and other extracted samples were filtered through $0.45 \mu \mathrm{m}$ nylon membrane $(25 \mathrm{~mm}$ diameter) using syringe filter. Estimation was done using Elite LaChrome2000 HPLC (Hitachi, Japan) system having C18 hydrophobic column $(25 \mathrm{~cm})$ and diode array detector as per the procedure of Pichaiyongwongdee and Haruenkit (2009). Temperature of column oven was maintained at $30^{\circ} \mathrm{C}$ and flow rate was 
maintained at $1 \mathrm{ml}$ per min. Eighty microlitre of membrane filtered juice/extract was taken for estimation. The estimation was carried out at $210 \mathrm{~nm}$ using $40 \%$ acetonitrile isocratically as mobile phase. The retention time (RT) and absorbance units were recorded of peak shoulders and the values were expressed in ppm using a standard curve of limonin (20-100 ppm).

For extraction of naringin from seed or peel of kinnow, 2.5 $\mathrm{g}$ of each tissue was homogenized with $50 \mathrm{ml}$ of Tris buffer $(0.1 \mathrm{M}$; $\mathrm{pH} 7.0)$. The broth was incubated at $35^{\circ} \mathrm{C}$ in a shaker (150 rpm) for $24 \mathrm{hr}$ and the resulting extract was filtered through two layers of muslin cloth and bloating paper and centrifuged at $7000 \mathrm{rpm}$ for 30 min. Kinnow juice was extracted using screw press and filtered through double layer of muslin cloth and centrifuged (Eltak, India) at $7000 \mathrm{rpm}$ for $30 \mathrm{~min}$. The resulting aqueous extracts of juice were again filtered through grade-1 filter paper and used as naringin extract. The extracted samples (peel, seed, and juice) were filtered through $0.45 \mu$ nylon membrane ( $25 \mathrm{~mm}$ diameter) using syringe filter. Eighty microlitre of membrane filtered juice/extract was taken for estimation. The estimation was carried out at $280 \mathrm{~nm}$ via RP-HPLC using $20 \%$ acetonitrile isocratically as mobile phase at $30^{\circ} \mathrm{C}$ as per the procedure of Pichaiyongwongdee and Haruenkit (2009). The retention time (RT) and absorbance units were recorded and the values were expressed in ppm using a standard curve of naringin (20-100 ppm).

Physico-chemical analysis of kinnow juice : Total soluble solids (TSS) of kinnow juice were estimated using brix meter (Atago Japan). Ascorbic acid was determined as per the procedure of (AOAC, 1984). Percent titratable acidity was estimated in terms of citric acid (Mr64) milli-equivalents as per the procedure of Ranganna (2000).

\section{Effect of various approaches on bitterness causing chemical constituents of kinnow juice:}

Bitterness index of different fruit portions: The manually separated seeds, albedo, flavedo, pomace and extracted juice were subjected to estimation of bittering factors, limonin and naringin, as per the procedures given above using HPLC.

Time of harvesting : Kinnow fruits were harvested at monthly intervals from September to April, their juice was extracted and the bittering constituents and other physico-chemical parameters were evaluated in kinnow juices as per the procedures given above.

$\mathrm{pH}$ and storage temperature: For storage study, the extracted kinnow juice was heated $\left(90^{\circ} \mathrm{C} ; 5 \mathrm{~min}\right)$, centrifuged $(7000 \mathrm{rpm} ; 10$ $\mathrm{min}$ ), adjusted to $\mathrm{pH} 3.0,4.0$ and 5.0 with citric acid and sodium hydrogen phosphate and stored at ambient $\left(20-26^{\circ} \mathrm{C}\right)$ and low temperature $\left(5 \pm 1^{\circ} \mathrm{C}\right)$. Since, limonin is responsible for delayed bitterness while storage, only limonin concentration was assessed at monthly interval in order to see the effect of $\mathrm{pH}$ and temperature on kinnow juice bitterness while storage.

Effect of various adsorbent treatments: The extracted juice was heated $\left(90^{\circ} \mathrm{C} ; 5 \mathrm{~min}\right)$ and centrifuged $(7000 \mathrm{rpm} ; 10 \mathrm{~min})$; the clear juice was further subjected to individual treatments: passing through the columns of T2 (silica gel), T3 (florisil), T4 (XAD16), and T5 (XAD7) (T1 being control juice). The clarified and centrifuged juice was passed through columns of various adsorbents (T2 to T5) of dimensions $2.5 \times 40 \mathrm{~cm}$ each and the juice was allowed to percolate down under gravitational force and assessed the effect of various physical treatments on bitterness causing constituents, physico-chemical composition and sensory quality of kinnow juice.

Development of process for kinnow juice de-bittering: Based on the inferences of results, a process was devised which involved manual removal of peel and seeds followed by centrifugation. An adsorbent filtration step was introduced in order to further reduce the bittering components via adsorption using activated charcoal. The juice was allowed adsorption (of bittering factors) by giving a contact time of $2 \mathrm{hr}$ between juice and activated charcoal with intermittent shaking followed by filtration through adsorbent using a vacuum pump.

Statistical analysis : Statistical analysis was done using complete randomized design (CRD). Juice extracted of multiple fruits from multiple trees was treated as one replicate and each replicate was repeated thrice. The SEm, C.D. and C.V. of ripening stage, treatments and interactions were calculated at $p \leq 0.05$ using OPSTAT statistical software.

\section{Results and Discussion}

Bitterness index of kinnow juice as affected by different fruit portions is presented in Table 1. Limonin and naringin were found to be the major bittering factors among different fruit parts. The concentration of each bittering factors varied among different fruit parts. Limonin was found to be the highest in seed with corresponding value of $224.37 \pm 5.58 \mathrm{ppm}$ followed by pomace $(114.91 \pm 2.26 \mathrm{ppm})$. Although limonin was not detectable in albedo part but its lowest concentration was found in juice $(20.33 \pm 1.56 \mathrm{ppm})$. On the other hand, naringin was found highest (13589.82 $\pm 6.86 \mathrm{ppm})$ in albedo portion and lowest $(105.67 \pm 0.95$ $\mathrm{ppm}$ ) in kinnow juice. There was statistically significant difference between various compartments for both bittering factors. Naringin is the primary water-soluble bittering component in the fruit membrane and albedo, which becomes extracted in juice during fruit processing (Puri and Kalra, 2005). It is quite common in pummelo, grapefruit, sour orange, and pumello hybrid natsudaidai and its threshold limit for acceptable taste is $20-50$ ppm for commercially processed citrus juices (Hasegawa et al., 1996). However, Guadagni et al. (1973) reported the threshold limit for naringin to the tune of $600 \mathrm{ppm}$. On the other hand, limonin is a highly oxygenated triterpenoid dilactone which occurs 
Table 1: Bitterness index in different portions of kinnow fruit

\begin{tabular}{lll}
\hline Sample & Limonin $(\mathbf{p p m})$ & Naringin $(\mathbf{p p m})$ \\
\hline Flavedo & $56.95 \pm 1.33$ & $13589.82 \pm 6.86$ \\
Albedo & - & $4037.83 \pm 9.18$ \\
Juice & $20.33 \pm 1.56$ & $105.67 \pm 0.95$ \\
Seed & $224.37 \pm 5.58$ & $710.82 \pm 4.67$ \\
Pomace & $114.91 \pm 2.26$ & $131.84 \pm 1.46$ \\
\hline
\end{tabular}

naturally in plants from the Rutaceae and Meliaceae families, and particularly abundant in the seeds (Roy and Saraf, 2006) and it causes bitter taste with threshold level of 5-6 ppm in orange juice (Guadagni et al., 1973). The concentration of limonin and naringin in kinnow juice has been reported to 7.5 and $249.75 \mathrm{ppm}$, respectively (Kaur et al., 2018). Each part of the fruit contained different amount of limonin being highest in seeds (9.50 $\left.\mathrm{mg} \mathrm{g}^{-1}\right)$ followed by peel $\left(4.69 \mathrm{mg} \mathrm{g}^{-1}\right)$ and juice $\left(0.128 \mathrm{mg} \mathrm{m}^{-1}\right)$ (Premi et al., 1995).

A number of physico-chemical changes take place as kinnow fruit ripens on the tree. Delaying harvesting of kinnow from September to April significantly reduced the concentration of bittering factors in processed juice. However, the juice was still not acceptable even from late harvested kinnows (Fig. 1). Naringin content in juice decreased from an initial value of 396.13 ppm to $146.2 \mathrm{ppm}$ when harvesting of fruit was delayed from September to April. A similar trend was followed for limonin content in juice which decreased from 52.37 to $12.7 \mathrm{ppm}$ in late harvested fruits (Fig. 1). Our findings are in close conformity to Khandelwal et al. (2006) who reported that limonin is available in the form of a non-bitter precursor (limonoate-A-ring lactone) in membranous juice sacs of citrus fruits and its conversion is accelerated by the action of enzyme LDLH which is prevalent in citrus fruits under acidic $\mathrm{pH}$ (Ferreira et al., 2008).

These results are in agreement with various researchers who have reported that naringin concentration is a function of degree of fruit maturity, with the least amount observed in ripened fruits (Puri et al., 2005). TSS increased while acidity decreased with harvesting time from September to April whereas ascorbic acid first increased and then decreased after January month harvesting (Fig. 2). Acidity of fruits showed a sharp decline in April harvesting and thereby resulted in insipid taste. TSS increased from an initial value of 7.43 to $12.63{ }^{\circ} \mathrm{B}$ while there was a corresponding decrease in \% titratable acidity from 1.41 to $0.41 \%$ (Fig. 2). Ascorbic acid content showed a bell shaped curve.

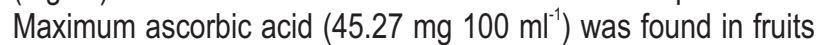
harvested in January while minimum (16.57 mg $100 \mathrm{ml}^{-1}$ ) recorded when harvesting was delayed by April (Fig. 2). The ascorbic acid content in kinnow has previously been reported in

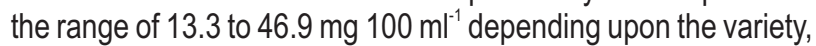
maturity and other storage conditions (Pruthi et al., 1983).

The data pertaining to changes in limonin mediated delayed bitterness during storage is elaborated in Table 2 . The limonin content was significantly affected by change in $\mathrm{pH}$ of juice under both the storage conditions (Table 2). The raising of $\mathrm{pH}$ had a positive effect on lowering the bitterness compound of stored kinnow juice. The juice having the highest $\mathrm{pH}$ had the lowest concentration of limonin in their juice (Table 2). There was significant difference between various treatments for bittering factors while other physico-chemical parameters (TSS and \% titratable acidity) were not affected significantly at $5 \%$ level. This implicated that the treatments did not jeopardize physicochemical and sensory parameters much. The concentration of limonin was also affected by storage duration and it increased with increase in storage period. However, this increase was more pronounced at ambient temperature then at low temperature storage. This may be due to more favorable conditions for activation of limonoate-Dring lactone hydrolase (LDLH) enzyme at ambient storage than at lower storage temperature (Maier et al., 1969). Although rise in $\mathrm{pH}$ decreased bitterness yet the acidic property of citrus juices was compromised slightly. The kinnow juice stored at $25^{\circ} \mathrm{C}$ developed full bitterness in four $h$ as against seven $h$ for juice stored at $12.5^{\circ} \mathrm{C}$ (Premi et al., 1995). The citrus fruit juice with higher $\mathrm{pH}$ had considerably lower bitterness. Similar results have been observed for limonin content in kinnow (Ranote and Bains, 1982) and Thai-tangerine juices (Chaisawadi et al., 1998) with higher $\mathrm{pH}$ values.

The extracted kinnow juice was heated, centrifuged, and further subjected to individual treatments (T2 to T5) in order to lower down bitterness. Passing of kinnow juice through various adsorbents significantly reduced the bittering compounds and invariably affected the changes in physico-chemical constituents and sensory quality of juice (Table 3). It is clear from the results that both naringin and limonin contents were found to be highest (185.36 and 29.84 ppm respectively) in untreated juice samples (T1) and lowest in XAD resin treated samples. However, maximum reduction in naringin (34.74 ppm) was obtained by XAD7 and that of limonin (3.94 ppm) was obtained by XAD16. Silica gel also reduced the bittering compounds to a substantial extent but it bleached the natural color of juice thereby adversely affecting the sensory quality of extracted juice. The bittering factors and other parameters were significant for the levels within variable and during interaction. However, interaction between $\mathrm{pH}$, temperature and storage period was found to be non-significantat $5 \%$ level (Table 3). Our results are in accordance to Kola et al. (2010) who used Amberlite-XAD-16HP and Dowex-OptiporeL285 to reduce bitterness to acceptable levels in Washington 


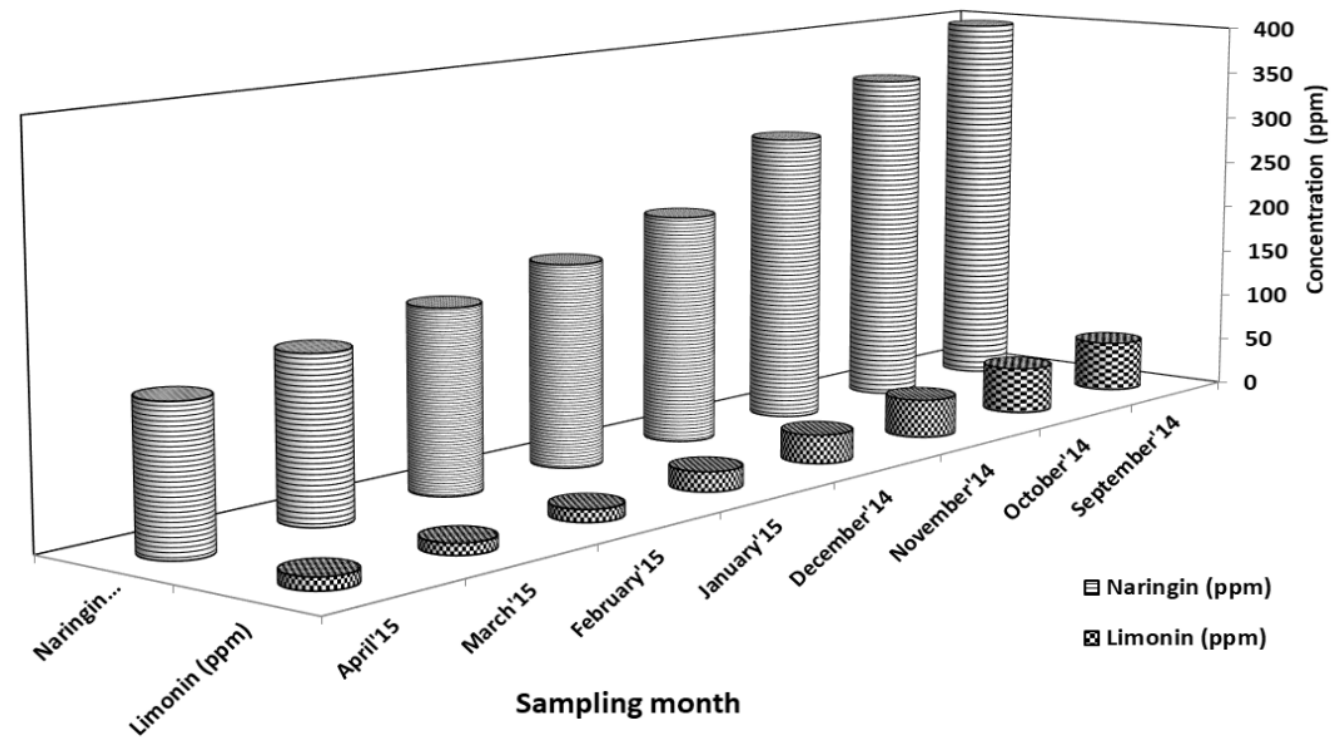

Fig. 1 : Bitterness index of kinnow juice during various months of harvesting.

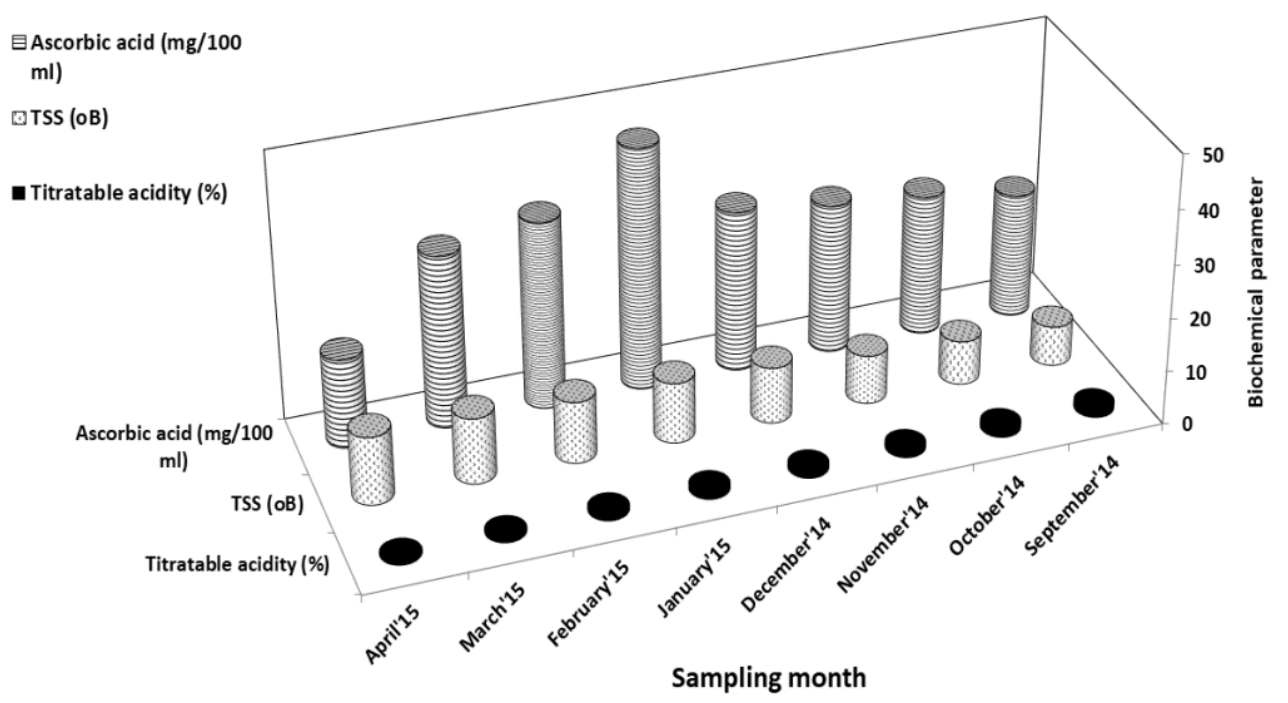

Fig. 2 : Physico-chemical changes in kinnow juice during various months of harvesting.

navel orange juices. They postulated that limonin concentration was reduced $97-100 \%$ with Amberlite-XAD-16HP and by $95-99 \%$ with Dowex-Optipore-L285 without compromising quality characteristics of orange juice. In the present studies also, TSS and acidity did not alter much by either of the adsorbent treatments and were found almost at par among treated and non-treated samples. Likewise, the highest reduction in limonin content was reported in kinnow juice treated with adsorbent XAD-16 (Premi et al., 1995). Activated magnesium silicate (florisil) has been shown to reduce limonin without adversely affecting nutritive quality of Thai-tangerine juice (Chaisawadi et al., 1998). Ribeiro et al. (2002) studied the selective removal of limonin and naringin from citrus juice by employing batch adsorption to different absorbent materials (activated diatomaceous earths, granulated activated carbon and synthetic neutral resins likeAmberlite XAD-4, XAD-7 and XAD-16). They observed that the highest adsorption efficiency for the bitter compounds was found with synthetic neutral resin, Amberlite XAD-7. Our results are in agreement with the findings of Ribeiro et al. (2002) but in contradiction to Premi et al. (1995). However, the cost of XAD resins remains a major limiting factor in de-bittering of citrus juices.

On the basis of data (Table 1), it was concluded that if seeds and peel (albedo+ flavedo) are manually/mechanically 
Table 2 : Kinetics of juice bitterness as influenced by $\mathrm{pH}$ and storage condition

\begin{tabular}{|c|c|c|c|c|c|c|}
\hline \multirow[t]{3}{*}{ Treatment type } & \multirow[t]{3}{*}{ Days after storage } & \multicolumn{3}{|c|}{ Storage behavior at different $\mathrm{pH}$ and temperature } & \multirow[t]{3}{*}{ Mean (pH) } & \multirow{3}{*}{$\begin{array}{l}\text { Mean (Temperatures) } \\
\text { at individual day basis }\end{array}$} \\
\hline & & \multicolumn{3}{|c|}{ Limonin (ppm) } & & \\
\hline & & 3.0 & 4.0 & 5.0 & & \\
\hline \multirow{6}{*}{$\begin{array}{l}\text { Low temperature } \\
\left(5 \pm 1^{\circ} \mathrm{C}\right)\end{array}$} & 0 & $22.52 \pm 0.64$ & $22.52 \pm 0.64$ & $22.52 \pm 0.64$ & 22.52 & 22.52 \\
\hline & 30 & $27.64 \pm 0.38$ & $26.45 \pm 0.39$ & $25.33 \pm 0.78$ & a 26.47 & 27.27 \\
\hline & 60 & $29.87 \pm 0.46$ & $28.94 \pm 0.71$ & $27.34 \pm 0.49$ & ' 28.72 & 30.21 \\
\hline & 90 & $32.93 \pm 0.16$ & $30.64 \pm 0.69$ & $28.02 \pm 0.37$ & c.f 30.53 & ${ }^{9} 32.45$ \\
\hline & 120 & $34.69 \pm 0.32$ & $32.20 \pm 0.52$ & $28.98 \pm 0.49$ & ${ }^{9} 31.96$ & ${ }^{\mathrm{h}} 33.80$ \\
\hline & $\begin{array}{l}\text { Mean (Days after } \\
\text { storage) }\end{array}$ & c.j’j29.53 & b28.15 & a,ì 26.44 & & \\
\hline \multirow[t]{7}{*}{ Ambient } & 0 & $22.52 \pm 0.64$ & $22.52 \pm 0.64$ & $22.52 \pm 0.64$ & 22.52 & \\
\hline & 30 & $30.08 \pm 0.24$ & $27.40 \pm 0.57$ & $26.74 \pm 0.48$ & ${ }^{\mathrm{d}} 28.07$ & \\
\hline & 60 & $34.57 \pm 0.77$ & $31.74 \pm 0.37$ & $28.80 \pm 0.28$ & 31.70 & \\
\hline & 90 & $38.99 \pm 0.84$ & $34.39 \pm 0.48$ & $29.70 \pm 0.57$ & e,h 34.36 & \\
\hline & 120 & $40.46 \pm 0.33$ & $35.14 \pm 0.14$ & $31.30 \pm 0.25$ & 35.63 & \\
\hline & $\begin{array}{l}\text { Mean (Days after } \\
\text { storage) }\end{array}$ & ${ }^{\mathrm{e}} 33.32$ & 30.24 & $\mathrm{d,k} 27.81$ & & \\
\hline & Mean (Temperatures) & 31.43 & ${ }^{\mathrm{i}} 29.20$ & i,k 27.13 & & \\
\hline
\end{tabular}

Value are mean of triplicate \pm S.E.; $n=3 ; a, b, c, d$ and $e$ are at par within each other in terms of interaction between $p H$ vs. storage period; $f, g$ and $h$ are at par within each other in terms of interaction between $\mathrm{pH}$ vs. temperature; i, $\mathrm{j}$ and $\mathrm{k}$ are at par with each other in terms of interaction between storage period vs. temperature

Interactions:

\begin{tabular}{llll} 
Factors & C.D. & SE(d) & SE(m) \\
Factor $(T)$ & 0.388 & 0.194 & 0.137 \\
Factor $(\mathrm{pH})$ & 0.475 & 0.237 & 0.168 \\
Interaction TXpH & 0.671 & 0.335 & 0.237 \\
Factor(DAS) & 0.613 & 0.306 & 0.217 \\
Interaction TXDAS & 0.867 & 0.433 & 0.306 \\
Interaction pHXDAS & 1.061 & 0.53 & 0.375 \\
\hline
\end{tabular}

Table 3 : Effect of adsorbents on compositional and sensory quality of kinnow juice

\begin{tabular}{llllll}
\hline Treatment code & Naringin $(\mathbf{p p m})$ & Limonin $(\mathrm{ppm})$ & TSS $\left({ }^{\circ}\right.$ Brix $)$ & Titratable acidity $(\%)$ & Sensory score \\
\hline T1 & $185.36 \pm 1.29$ & $29.84 \pm 0.61$ & ${ }^{\mathrm{b}} 12.13 \pm 0.01$ & $0.78 \pm 0.01$ & 3.1 \\
T2 & $56.28 \pm 0.74$ & $11.74 \pm 0.46$ & ${ }^{\mathrm{a}} 11.70 \pm 0.03$ & $0.77 \pm 0.01$ & 5.5 \\
T3 & $98.76 \pm 0.22$ & $14.52 \pm 0.37$ & $\mathrm{a} 11.62 \pm 0.08$ & $0.77 \pm 0.006$ & 5.7 \\
T4 & $69.40 \pm 0.88$ & ${ }^{\mathrm{a}} 3.33 \pm 0.23$ & $\mathrm{~b} 12.28 \pm 0.16$ & $0.77 \pm 0.007$ & 7.3 \\
T5 & $34.74 \pm 0.67$ & $3.94 \pm 0.36$ & ${ }^{\mathrm{b}} 12.42 \pm 0.14$ & $0.80 \pm 0.003$ & 8.1 \\
C.D. & 2.669 & 1.354 & 0.326 & - & \\
SE $(\mathrm{m})$ & 0.836 & 0.424 & 0.102 & 0.008 & \\
SE $(\mathrm{d})$ & 1.183 & 0.6 & 0.144 & 0.012 & \\
C.V. & 1.629 & 5.799 & 1.47 & 1.877 & \\
\hline
\end{tabular}

Value are mean of triplicate \pm S.E.; $n=3 ; a=$ at par with each other; $b=$ at par with each other

removed before juice extraction, we can cut down a major portion of bitterness being drifted in kinnow juice while processing due to tissue disruption. This step when combined with adsorbent fltration treatment, further reduced the concentration of bittering compounds in the final juice. The complete process for debittering of kinnow juice involved following sequential steps: manually separating peel (albedo+flavedo) and seeds; juice extraction; initial heating for $90^{\circ} \mathrm{C}$ for $5 \mathrm{~min}$; centrifugation $(7000$ rpm; 10 min); treatment with adsorbent/ activated charcoal for $2 \mathrm{~h}$; re-addition of centrifuged pulp (1\%); adding LDLH inhibitor (294 mg I glutamic acid or $745 \mathrm{mg}$ EDTA per liter of juice) and permitted color, setting up TSS $\left(14.5^{\circ} \mathrm{B}\right)$ and acidity $(0.75 \%)$, hot filling, pasteurization, cooling and storage of juice bottles in cool and dry place. Following absorbent filtration step, naringin content was 
reduced to $62.69 \pm 2.49 \mathrm{ppm}$ while limonin content was reduced almost to negligible value. Addition of charcoal did not affect other physicochemcial composition of kinnow juice considerably. TSS, acidity and ascorbic acid content of treated juice was slightly reduced from $12.73 \pm 0.07$ to $12.20 \pm 0.11^{\circ} \mathrm{B}, 0.56$ to $0.49 \%$ and 16.57 to $3.76 \mathrm{mg} / 100 \mathrm{ml}$, respectively. An inhibitor of LDLH activity was added to curtail activity of LDLH in this de-bittering process. The inhibitor study was performed in a separate experiment on purified LDLH of kinnow seeds, the data of which are not shown here and published elsewhere (Kumar et al., 2018).

It may be inferred from the present study that crushing of seeds and peel was the main factor contributing towards the development of bitterness in the freshly extracted juice of kinnow. Removal of seed and peel, centrifugation and adsorbent filtration of extracted juice had reduced the bitterness below the threshold limit. Hence, this process can be established for kinnow juice debittering.

\section{Acknowledgments}

The work submitted for publication is part of project no. IXX10191 approved by the Institute and funded by Indian Council of Agricultural Research. The authors are thankful to Indian Council of Agricultural Research for funding this research as Institute project.

\section{References}

AOAC: Official Methods of Analysis; AOAC, Washington, DC: Association of Official Analytical Chemists (1984).

Chaisawadi, S., W. Aiemphasit, N. Chommanard and S. Kulamai: Debittering of lime juices with food additives. J. Sci. Fac. Chiang MaiUniv., 25, 65-70 (1998).

FAO: FAOSTAT: Food and Agriculture Organization of the United Nations (2017)

Ferreira, L., C. Afonso, H. Vila-Real, A. Alfaia and M.H.L. Rebeiro: Evaluation of the effect of high pressure on naringin hydrolysis in grapefruit juice with naringinase immobilised in calcium alginate beads. Food Technol. Biotechnol., 46, 146-150 (2008).

Guadagni, D.G., V.P. Maier and J.G. Turnbaugh: Effect of some citrus juice constituents on taste thresholds for limonin and naringin bitterness. J. Sci. Food Agric., 24, 1277-1288 (1973).

Hasegawa, S. and V.P. Maier: Biochemistry of limonoid citrus juice bitter principles and biochemical debittering processes. In: Bitterness in Foods and Beverages (Ed.: R.L. Rouseff). Elsevier, New York, USA, p. 293-308 (1990).

Hasegawa, S., M.A. Berhow and C.H. Fong: Analysis of bitter principles in Citrus. In: Modern Methods of Plant and Fruit Analysis, Vol. 18. Springer-Verlag, Berlin, pp. 59-80 (1996).

Kaur, M., P. Sahota, N. Sharma, K. Kaur and B. Sood: Enzymatic production of debittered kinnow juice and beverage. Int. J. Curr. Microbiol. App. Sci., 7, 1180-1186 (2018).

Khandelwal, P., V. Kumar, N. Das and S.M. Tyagi: Development of process for preparation of pure and blended kinnow wine without de-bittering kinnow mandarin juice. Int. J. Food Safety, 8, 24-29 (2006).

Kola, O., C. Kaya, H. Duran and A. Altan: Removal of limonin bitterness by treatment of ion exchange and adsorbent resins. Food Sci. Biotechnol., 19, 411-416 (2010).

Kumar, S., R. Kumar, P.C. Sharma and A. Pal: Purification and characterization of Limonoate-D-ring lactone hydrolase from kinnow fruits grown in Punjab, India. J. Environ. Biol., 39, 175-181 (2018).

Maier, V.P., S. Hasegawa and E. Hera: Limonin D-ring-lactone hydrolase-A new enzyme from citrus seeds. Phytochemistry, $\mathbf{8}$, 405-407 (1969).

National Horticulture Board: nhb.gov.in/area-pro/Indian\%20 Horticulture\% 2015.pdf. (accessed November 11, 2016) (2015).

Pichaiyongwongdee, S. and R. Haruenkit: Comparative studies of limonin and naringin in different parts of pummel [Citrus grandis (L.) Osbeck] cultivars grown in Thailand. Kasetsart J. (Nat. Sci.), 43, 28-36 (2009).

Premi, B.R., B.B. Lal and V.K. Joshi: Efficacy of various techniques for removing bitter principles in kinnow juice. J. Food Sci. Technol., 32, 332-335 (1995).

Pruthi, J.S., J.K. Mann and M.S. Teotia: Studies on utilization of kinnow and malta oranges. J. Food Sci. Technol., 21, 123-127 (1983).

Puri, M. and S. Kalra: Purification and characterization of naringinase from a newly isolated strain of Aspergillus niger 1344 for the transformation of flavonoids. World J. Microbiol. Biotechnol., 21, 753-758 (2005).

Puri, M., H. Kaur and J.F. Kennedy: Covalent immobilization of naringinase for the transformation of a flavonoid. J. Chem. Technol. Biotechnol., 80, 1160-1165 (2005).

Putnik, B., F.J. Barba, J.M. Lorenzo, D. Gabric, A. Sphigelman, G. Cravotto and D.B. Kovacevic: An integrated approach to mandarin processing: Food safety and nutritional quality, consumer preference and nutrient bioaccessibility. Comprehensive Rev. Food Sci. Food Safety, 16, 1345-1358 (2017).

Ranganna, S.: Handbook of Analysis and Quality Control for Fruit and Vegetable Products. Tata McGraw Hill Publishing Co. Ltd., New Delhi (2000).

Ranote, P.S. and G.S. Bains: Juice of kinnow fruit. Indian Food Packer, 36, 23-33 (1982).

Ribeiro, M.H.L., D. Silveira and D.S. Ferreira: Selective adsorption of limonin and naringin from orange juice to natural and synthetic adsorbents. Eur. Food Res. Technol., 215, 462-471 (2002).

Roy, A. and S. Saraf: Limonoids: Overview of significant bioactive triterpenes distributed in plant kingdom. Biol. Pharmac. Bull., 29, 191-201 (2006).

Sahota, P.P. and A. Kaur: Characterization of enzyme naringinase and the production of debittered low alcoholic kinnow (Citrus reticulata Blanco) beverage. Int. J. Advanced Res., 3, 1220-1233 (2015).

Shaw, P. E. and C.W. Wilson: Reduction of bitterness in grapefruit juice with $\beta$-cyclodextrin polymer in a continuous flow process. J. Food Sci., 50, 1205-1207 (1985).

Singh, S.V., A.K. Gupta and R.K. Jain: Adsorption of naringin on nonionic (neutral) macroporous adsorbent resin from its aqueous solutions. J. Food Eng., 86, 259-271 (2008). 